IRA-International Journal of Management \&

Social Sciences

ISSN 2455-2267; Vol.17, Issue o3 (Q.3 2021)

Pg. no. 81-88.

IRA Academico Research

\title{
Effects of Consumer Purchasing Power on Buying Preferences in Shopping Malls in Kenya: A Case Study of Nakuru County
}

\author{
Monicah Mugambi ${ }^{1 \#}\left({ }^{10}\right.$, Robert Obuba $\mathrm{PhD}^{2}$ \\ ${ }^{1}$ Masters of Business Administration, Mount Kenya University, Kenya. \\ ¿2Lecturer School of Business and Economics, Mount Kenya University, Kenya.
}

\#corresponding author

Type of Work: Peer Reviewed.

DOI: https://dx.doi.org/10.21013/jmss.v17.n3.p1

\section{How to cite this paper:}

Mugambi, M., Obuba, R. (2021). Effects of Consumer Purchasing Power on Buying Preferences in Shopping Malls in Kenya: A Case Study of Nakuru County. IRA-International Journal of Management \& Social Sciences (ISSN 2455-2267), 17(3), 81-88. DOI: https://dx.doi.org/10.21013/jmss.v17.n3.p1

(C) IRA Academico Research.

(c) EY-No $_{\text {B }}$ This work is licensed under a Creative Commons Attribution-NonCommercial 4.0 International License subject to a proper citation to the publication source of the work.

Disclaimer: The scholarly papers as reviewed and published by IRA Academico Research are the views and opinions of their respective authors and are not the views or opinions of IRA Academico Research. IRA Academico Research disclaims any harm or loss caused due to the published content to any party.

IRA Academico Research is an institutional publisher member of Publishers International Linking Association Inc. (PILA-CrossRef), USA. IRA Academico Research is an institutional signatory to the Budapest Open Access Initiative. Hungary advocating the open access of scientific and scholarly knowledge. IRA Academico Research is a registered content provider under Open Access Initiative Protocol for Metadata Harvesting (OAl-PMH).

The journal is indexed \& included in WorldCat Discovery Service (USA), CrossRef Metadata Search (USA), WorldCat (USA), OCLC (USA), Open J-Gate (India), EZB (Germany) Scilit (Switzerland), Airiti (China), Bielefeld Academic Search Engine (BASE) of Bielefeld University, Germany, PKP Index of Simon Fraser University, Canada. 


\section{ABSTRACT}

Many internal and external factors influence consumer decision-making when it comes to the purchase and use of various products and services. The attributes of the product itself, the brand, and the container in which it is encased is the most important and critical external variables. The study adopted a cross-sectional survey involving hotels, beauty parlours, electronics dealers, boutiques as well as entertainment outlets. The researcher targeted 305 business premises operating in 30 shopping malls from which a sample of 62 premises and 310 customers were sampled using stratification, Simple Random Sampling (SRS) and convenient sampling. The data was collected through the use of questionnaires. Descriptive statistics was employed and results were presented in tables and charts with the help of Statistical Packages for Social Sciences (SPSS) for analysis purposes. The influence of consumer purchasing power on the preference of shopping malls was tested using regression, correlation and Chi-square methods at 5\% levels of effect. From the study findings, the researcher Establish that purchasing power, personal preference has been found to play an important role in influencing consumer's preferences and bias towards shopping malls. An overwhelming number of the consumers recognized the importance of group influence on their choice of the shopping mall. This helped the researcher draw a conclusion and formulate recommendations informing policies and marketing strategies that are essential to marketers in the shopping malls and other related business facilities in line with consumer purchasing power.

Keywords: Consumer, Consumer preferences, cross-sectional survey and consumer purchasing power

\section{Background of the Study}

Many internal and external factors influence consumer decision-making when it comes to the purchase and use of various products and services. The attributes of the product itself, the brand, and the container in which it is encased is the most important and critical external variables. External features of a product or service that relate to its purchase or consumption, such as price information, package or product look, user imagery, and usage imagery, are examples of non-product-related attributes (Mullen, 1995).

Consumer perceptions of price, quality, and value are important factors in determining behaviour and product selection (Bishop et al., 1984). They are the most important aspects that influence consumer perception. The majority of consumer criteria linked to attitude fall into one of three categories: personality, perception, and socioeconomic status (Batra and Sinha, 2000). Buyer perceptual factors that have been recognized incorporate value quality discernment, seen quality, esteem awareness, value cognizance, seen value reasonableness, shrewd customer self-insight, knowledge of items, brand devotion, the apparent danger related with the buy, hazard averseness, and general arrangement inclination (Garretson et al.,2002).

In Kenya, there used to be few shopping malls but their number is increasing rapidly. A study that investigated the factors affecting consumer choice in retail outlets in Nairobi, established that the products' types and proximity of the stores were the main factors influencing the consumer choice, thus showing the marketing mix role in the retail sector (Njoka, 2012).

\section{Statement of the Problem}

Knowing consumers' buying motivations, and developing close relationships with them, are critical means of competition for firms in today's increasingly crowded marketplace (Mokgabudi, 2012). Of special significance in the case of economies relying significantly on imported goods are consumer attitudes towards foreign and domestic products, and the ethnocentricity that affects them (Huddleston P, 2001). Trade policies have provided consumers with more foreign product choices than ever before. Consequently, their attitudes toward products originating from foreign countries have been of interest to international business and consumer behaviour researchers for decades (Mokgabudi, 2012).

With the growing number of shopping malls in Nakuru County, increased competition for customers is evident. Increased changes in consumer behaviours have resulted in shopping mall owners having to change the consumer range of choices on goods and services in order to satisfy them thereby gaining loyalty. It is against this backdrop that the researcher is conducted this study to establish the effects of consumer purchasing power on the preference of shopping malls in Kenya.

\section{General Objective}

The general objective of the study is to establish the effects of consumer purchasing power on the preference of shopping malls in Kenya.A case of Nakuru County. 
Significance of the Study

The study findings will be of great importance to the existing shopping malls and the findings will help them get further insight into the customers' perception. The findings also will help the stakeholders focus more on continuous improvement by avoiding the negative factors which will be identified in this study.

This paper will also be used as a guideline for the researchers that will have a basic idea of how the factors brand image, perceived quality, product availability, product variety, location and price play important roles in the decision making of the customers when choosing a shopping mall.

\section{LITERATURE REVIEW}

\section{Consumer Purchasing Power}

In a study on the relationship between shopping malls preference and consumer behaviours, it was established that the consumers' choice for a certain mall is not rational and it's not based on the pricing but rather on the basis of satisfying the consumer's economic, social and psychological needs (Mokgabudi, 2012). However, the price of products is also one of the most important factors that the consumer considers when evaluating the product/brand before purchase (Hansen, 2005). Consumers have a variety of outlets from where they can purchase products and services. Some of the outlets include shopping malls, hawkers' stands, kiosks, general stores and wholesale outlets. Consumers have a tendency to prefer shopping malls to other outlets when purchasing products and services.

A shopping mall regularly contains new produce, dairy and heated merchandise offices alongside rack space held for quick nourishments and other bundled products. It additionally has non-food things, for example, family cleaners, drug store items and pet supplies. Most shopping centres likewise sell an assortment of family unit items that are burned-through routinely, for example, liquor (where allowed) and attire. Shopping centres additionally have markets that are self-administration stores offering a wide assortment of nourishments and family stock and coordinated into offices. They are bigger in the estimate and have a more extensive determination than a customary supermarket which is more modest and is restricted in the scope of the product than a hyper-market which is a combination of shopping malls and department stores (Mokgabudi, 2012).

Although it is a very hard concept to understand, it has been proven that the consumers' taste can be measured effectively. It has also been established that the study can shed more insight on the various choices made by the consumers when they decide on a particular seller against the other. In other cases, they might decide to continue consuming from the same dealer thus cementing the relationship further. In addition, the studies established that the various concepts related to the customer inclinations are worse characterized yet they are shaped inside the way toward picking. This proposed that the various assignments and settings feature the various parts of the client alternatives, focusing on the various contemplations prompting choices that are not in a certain pattern (Novemsky, Dhar, Schwarz, \& Simonson, 2007).

\section{Motivation Theories}

Motives arouse individuals thereby increasing their readiness to respond. Motives may well determine whether or not a customer will stop in a store. Rational and practical things do not always motivate consumers but often emotional and irrational drives sometimes do. There are two types of motives; social motives, which arise from interaction with the environment and psychological motives, which arise from the natural biological mechanism. Personal and social motives both influence consumers' shopping activities in different ways. The quality of the shoppers" rationale likewise has all the earmarks of being a significant decidedly related component in their pleasure and excitement in the commercial centre and with fulfilment as far as retail inclination. As per our examination, it was discovered that purchasers search for experiential and enthusiastic reasons just as for merchandise, administrations and data.

Some shopping behaviour may be attributed to variety-seeking kind of behaviour, however, with high optimum levels, new environments can be explored while with lower optimum levels consumers tend to feel comfortable with what is more familiar. The theory of motivation proposed by Maslow can also be used to understand shoppers' behaviour. Maslow considered the variables which prompted an extreme objective of accomplishing self-realization or satisfaction. He contended that assuming a few higher needs in the hierarchy were not satisfied, then the lower need would dominate behaviour.

Therefore if the individuals are able to satisfy their basic needs then the retailer will have to understand the need to offer other products that fulfil other higher needs such as self-improvement, attainment of individuality, status within the society and deeper meaning in life. Therefore these kinds of products act as motivation and shopping 
malls position their stores to appeal to different audience preferences based on the merchandise, the quality and the price.

\section{Conceptual Framework}

The study will be guided by the conceptual framework is as shown in Figure 1.

Independent Variables

\begin{tabular}{|l|l|l|}
\hline Customer Purchasing Power & \multicolumn{1}{l|}{ Preference of Shopping Mall } \\
- Product prices & - No of visits \\
- Consumer income levels & - The length of repeated buying \\
- No of Products accessible & - Customer satisfaction \\
\hline
\end{tabular}

\section{Figure 1: Conceptual Framework}

The conceptual framework describes the relationship between the Customer Purchasing Power determinants and the preference of shopping malls. The dependent variable will be the preference of shopping mall whose indicators will be the frequency of visits, length of stay during visits by the consumers as well as their perceived satisfaction with the shopping mall facilities and products, while the independent variable is Customer Purchasing Power with the indicators; product prices, consumer income levels and no of products accessible.

\section{METHODOLOGY}

\section{Research Design}

The study adopted a cross-sectional survey targeting shopping malls in Nakuru County that host a variety of business premises and products that included goods and services (Nassiuma, 2000). Surveys were the most suitable, cheap and easy to administer method of data collection.

\section{Study Area}

The study focused on shopping malls in Nakuru County which is currently the fourth largest county in Kenya. Nakuru county growth rate is at $13 \%$, the fastest growing in Africa. It has had a rapid economic expansion overtaking Nairobi which is estimated to have an annual growth rate of $7 \%$.

\section{Target Population}

The researcher targeted consumers who are within Nakuru County and shop in the shopping malls in Nakuru County as well as the visiting consumers who reside out of Nakuru. There are almost 30 shopping malls in Nakuru County. The research targeted consumers in different business premises found in the shopping malls namely; hotels (60), beauty parlours (93), electronics dealers (47), boutiques (75) and entertainment outlets (30). The data was derived from Nakuru county business portal statistics and the Kenya open data statistics. Table 1 below shows the distribution of the target population. The target population distribution is displayed in Table.

Table 1: Distribution of Target population

\begin{tabular}{cc}
\hline Type of Business Premise & Number \\
\hline Hotels & 60 \\
Beauty parlours & 93 \\
Electronics dealers & 47 \\
Boutiques & 75 \\
Entertainment outlets & 30 \\
\hline Total & 305 \\
\hline
\end{tabular}

\section{Sampling Techniques and Sample Size}

The researcher used multistage sampling techniques that involved the selection of the shopping mall, business premise and hence the consumers (Orodho \& Reuben, 2002). The shopping mall was sampled using purposive 
sampling as the researcher sampled only shopping malls with all the targeted business premises namely; hotels, beauty parlours, electronics dealers, boutiques as well as entertainment outlets. The business premises were selected using stratified with the premises categorized into the 5 strata mentioned in Table 1 above and $20 \%$ of all the premises selected using Simple Random Sampling (SRS) which is between 10-30\% (Mugenda, 2013). Clients present at the selected premises will be selected using convenient sampling to get 5 consumers per premise. This resulted in a total of 62 selected business premises and 310 which is representative. The sample size distribution is shown in Table 2.

Table 2: Distribution of Sample Size

\begin{tabular}{cccc}
\hline Type of Business Premise & Number & Selected Premise (20\%) & $\begin{array}{c}\text { Selected } \\
\text { Consumers }\end{array}$ \\
\hline Hotels & 60 & 12 & 60 \\
Beauty parlours & 93 & 19 & 95 \\
Electronics dealers & 47 & 10 & 50 \\
Boutiques & 75 & 15 & 75 \\
Entertainment outlets & 30 & 6 & 30 \\
\hline Total & $\mathbf{3 0 5}$ & $\mathbf{6 2}$ & $\mathbf{3 1 0}$ \\
\hline
\end{tabular}

\section{Research Instrument}

An undisguised questionnaire was used to collect data. This questionnaire was having three sections (Dehn, Reinikka, \& Svensson, 2002). Section A consisted of close-ended questions to gather information on shopping mall consumers' personal and demographic characteristics. Section B consisted of information on consumer behaviours. Section $\mathrm{C}$ entailed the factors that consumers could consider important in order to prefer shopping in a given shopping mall. The researchers used matrix questions and a five-point Likert scale to identify the degree of importance of factors that determines store patronage from the consumers' perspective.

\section{Reliability}

Reliability is the degree to which a research instrument is able to produce consistent results or data after a repeat trial on the variables (Drost, 2011). The pilot study was used to check for the reliability of the mentioned research instruments. The method involved 5 customers in malls within Nakuru. Cronbach Alpha test will be employed and a result of alpha greater than 0.7 concluded a consistency for the research instruments meaning strong reliability (Santos, 1999).

\section{Validity of research instruments}

Validity in research refers to the degree to which a measure does what it is intended to do and focuses on the accuracy and meaningfulness of the findings considering the variables under observation (Van Teijlingen \& Hundley, 2002). In this process, the questionnaires were taken through a pilot phase; identifying vague questions with respect to the overall research objectives. The purpose of eliminating the vague questions is to ensure that the questionnaire elicits relevant information only from the respondents. Amends were then be made to the vague question before the collection of data is rolled out.

\section{Data Collection Procedures}

Data collection involved the use of questionnaires for literate respondents and researchers administered questionnaires to cater for those who could easily interpret the questions. The questionnaires were administered to the respondents present at the shopping mall. The questionnaires were filled as the researchers and research assistants wait in order to reduce non-response rates.

\section{Data Analysis Techniques}

The study is expected to give results to quantitative data. Data editing was done to eliminate any sampling and non-sampling errors that may tamper with the findings. These errors include; non-response, coverage, measurement and processing errors. This prevented any form of biased estimations. The data were analyzed through the use of the statistical packages for social sciences (SPSS) from IBM. mean, frequencies, median, mode and percentages commonly known as descriptive statistics will be used to make a summary of the research findings. Finally, the results will be presented in tables and charts. To enable the researcher to analyse the relationship between consumer purchasing power and shopping mall preference, inferential statistics namely; regression, and correlation. 


\section{Response rate}

A study responses rate is defined as the ratio of respondents who actually completed the questionnaires to the total sample expressed as a percentage. A response rate of more than 50\%, according to Mugenda and Mugenda (2003), is appropriate for statistical reporting. The study's author collected 224 complete questionnaires out of 310 which were handed over to the respondents, representing $72.25 \%$ as the response rate.

The response rate was tabulated as shown below

Table 3: Response Rate

\begin{tabular}{cccc}
\hline & Premises & Frequency & Per cent \\
\hline \multirow{4}{*}{ Valid } & Hotel & 15 & 6.7 \\
& Electronic dealers & 82 & 36.6 \\
& Beatty Parlour & 78 & 34.8 \\
& Boutique & 34 & 15.2 \\
& Others & 15 & 6.7 \\
Total & $\mathbf{2 2 4}$ & $\mathbf{1 0 0 . 0}$
\end{tabular}

The results in Table 3 shows the response rate for each of the five categories of premises in each shopping mall, hotel, electronic dealers, beauty parlour, boutique and other categories not listed. Electronic dealers and beauty parlours had the highest response rate of $36.6 \%$ and $34.8 \%$ respectively.

Purchasing power and influence on the influence on mall preference

Customer buying power was listed as one of the variables that influence customer demand for shopping malls in the report. To do so, the researchers used a Likert scale to determine how often market buying force impacts mall choice.

For each argument, mean scores and standard deviation were calculated and summarized in Table. 4 below.

Table 4: Purchasing and effect on the preference of shopping malls

\begin{tabular}{ccc} 
Aspects of purchasing power & Mean & Std. deviation \\
\hline Products in the shopping mall are of affordable prices. & 2.83 & 1.075 \\
I can be able to purchase the required quantity/amount of product & 2.85 & 1.072 \\
A variety of products to choose from are available in the shopping & 2.98 & 0.937 \\
mall & 2.92 & 1.012 \\
With my level of income, I am able to access relevant products & 2.91 & 0.980 \\
Most of the products that I require are present & \\
\hline
\end{tabular}

From the findings, the respondents were observed to be neutral with most of the statements on purchasing power and its influence on consumer preference in shopping malls. However, the availability of a variety of products in the shopping mall and their affordability were rated as the highest purchasing power dimension factors that influence consumer's shopping mall preference with mean scores of 2.98, 2.92 and 2.91 respectively. The extent of the product in the shopping mall are of affordable price and its effect on shopping mall preference was rated at fifth with a mean of 2.83 while the idea of buying the right quantity in the shopping mall was rate closely at fourth position with a mean score of 2.85. From the above analysis, it is apparent that the consumers consider availability and variety of products as one of the main success factors of consumer shopping mall preference.

\section{Regression Model}

\section{Regression Analysis on purchasing power Vs preference of shopping malls}

To assess the significance of the relationship between buying power and customer preference for shopping malls, regression analysis was used. The results of the Analysis of Variance (ANOVA) on buying power versus shopping mall choice are shown in table 5. The significance of the $\mathrm{F}$ is 0.000 less than 0.05 , meaning that the predictor coefficient is at least not equal to zero, according to the ANOVA results for regression coefficients. This also means that the model is a good match. 
Table 5: ANOVA purchasing power

\begin{tabular}{|ll|r|r|r|r|r|}
\hline \multicolumn{7}{|c|}{ ANOVA $^{\mathrm{a}}$} \\
\hline 1 & $\begin{array}{r}\text { Sum of } \\
\text { Squares }\end{array}$ & \multicolumn{1}{c|}{$\mathrm{df}$} & \multicolumn{1}{c|}{$\begin{array}{c}\text { Mean } \\
\text { Square }\end{array}$} & \multicolumn{1}{c|}{$\mathrm{F}$} & Sig. \\
\hline 1 & $\begin{array}{l}\text { Regressio } \\
\mathrm{n}\end{array}$ & 61.019 & 1 & 61.019 & 561.390 & $.000^{\mathrm{b}}$ \\
& Residual & 1.296 & 222 & 1.087 & & \\
& Total & 62.315 & 223 & & & \\
\hline
\end{tabular}

a. Dependent Variable: preference of shopping mall

\section{b. Predictors: (Constant), Purchasing power}

The beta coefficients of buying power versus shopping mall choice were also calculated in the analysis. The coefficient of purchasing power is 0.921 , according to Table 6 . This coefficient has a t statistic of 0.237 and a pvalue of 0.000 , which is less than 0.05 . At a $95 \%$ level of trust, this p-value confirms the importance of the coefficient of purchasing power. As a result, we can infer that buying power affects shopping mall choice and therefore has a significant positive relationship.

Table 6: Coefficients Purchasing Power

\begin{tabular}{|c|c|c|c|c|c|c|}
\hline \multicolumn{7}{|c|}{ Coefficients $^{a}$} \\
\hline \multirow[b]{2}{*}{ Model } & & \multicolumn{2}{|c|}{$\begin{array}{c}\text { Unstandardized } \\
\text { Coefficients }\end{array}$} & \multirow{2}{*}{\begin{tabular}{|c}
$\begin{array}{c}\text { Standardiz } \\
\text { ed } \\
\text { Coefficient } \\
\text { s }\end{array}$ \\
Beta \\
\end{tabular}} & \multirow[b]{2}{*}{$\mathrm{t}$} & \multirow[b]{2}{*}{ Sig. } \\
\hline & & $B$ & Std. Error & & & \\
\hline \multirow[t]{2}{*}{1} & (Constant) & 2.903 & .197 & & 14.764 & .000 \\
\hline & $\begin{array}{l}\text { Purchasin } \\
\text { g power }\end{array}$ & .921 & .065 & .016 & .237 & .813 \\
\hline
\end{tabular}

a. Dependent Variable: preference of shopping mall

\section{Discussions}

The findings of this study support the study conducted by Mokgabudi, (2012) that suggested that the consumers' choice for a certain mall is not rational and it's not based on the pricing but rather on the basis of satisfying the consumer's economic needs. Understanding the influence of purchasing power on the preference of shopping malls can help the consumer to make the decision of the shopping choice based on affordability. The study found out that personal preference influences the preference of shopping malls thereby vindicating the findings of Munthiu, (2009) who observed that features such as size, colour, consistency, and packaging among others; label, name, use instructions that come with the product and customer services offered to the person when purchasing and using the particular product that triggers the taste of a consumer. These dimensions of personal preference will affect the consumer's choice of a shopping mall.

\section{Summary of Findings}

Purchasing power on the preference of shopping malls

The study described the buying power of customers as one of the shopping malls as one of the things that influence consumer choice. The study found that the availability of a wide range of goods in the shopping mall, as well as their affordability, are the most important buying power dimension factors that affect a consumer's shopping mall choice. The study did note, however, that the affordability of the product was rated very low as a dimension of consumer power, with a mean of 2.83 and a standard deviation of 1.075 , indicating that the respondents' opinions did not differ greatly. The regression coefficients significance $\mathrm{F}$ of 0.000 , which is less than 0.05 , indicates that the predictor coefficient is not equal to zero, according to the Analysis of Variance 
(ANOVA) on buying power versus shopping mall choice. This indicates that the model is a good match. The beta coefficients of buying power versus shopping mall choice were also calculated in the analysis. The coefficient of buying power was determined to be 0.921 . This coefficient has a t statistic of 0.237 and a p-value of 0.000 , which is less than 0.05 . At a $95 \%$ level of trust, this p-value confirms the importance of the coefficient of purchasing power. As a result of the research, it was discovered that buying power has a huge impact on shopping mall preferences in Nakuru County.

\section{Recommendations}

The study recommends to mall managers need to have good and accommodating recreation facilities to attract more shoppers to the mall. The study further recommends to shopping mall tenants introduce affordable prices to most of their products to improve consumer affordability.

\section{Suggestions for further study}

The consumer purchasing power determinants on the preference of shopping malls were applied among malls in Nakuru County, to improve the validity of this study's results; another study should be conducted in a different mall. The greater the number of studies that accompany this one, the more accurate the results can be generalized.

\section{References}

[1]. Dehn, J., Reinikka, R., and Svensson, J. (2002). Overview instruments for evaluating administration conveyance. Advancement Research Group. The World Bank.

[2]. Drost, E. A. (2011). Legitimacy and dependability in sociology research. Instruction Research and Perspectives, Retrieved from: https://www.researchgate.net/distribution/

[3]. Gebhardt, W. R., Lee, C., and Swaminathan, B. (2001). Toward an inferred cost of capital. Diary of bookkeeping research, Pages 39, 135-176.

[4]. Hansen, T. (2005). Points of view on customer dynamic: An incorporated methodology. Diary of Consumer Behavior, Pages 4, Pages 420-437.

[5]. Hansson, S. O., and Grüne-Yanoff, T. (2008). Inclinations Change. Hypothesis and Decision, New York, Springer Publications.

[6]. Khan, U., Zhu, M., and Kalra, A. (2011). At the point when compromises matter: The impact of decision interpretation on setting impacts. Diary of Marketing Research, Pages 48, Pages 62-71.

[7]. Mokgabudi, L. R. (2012). The effect of shopping center advancements on shopper conduct in municipality regions. Citeseer.

[8]. Mugenda, O. (2013). MugendaA. G (1999). Exploration techniques, Quantitative and Qualitative Approaches. Nairobi: Act Press.

[9]. Munthiu, M. C. (2013). The Buying Decision Process and Types of Buying Decision Behavior.Economic Sciences; Retrieved from: https://www.semanticscholar.org/paper/

[10]. Nassiuma, D. (2000). Review Sampling: Theory and Practice, Nairobi: Nairobi University Press

[11]. Njoka, I. K. (2012). Elements affecting shopper selection of markets in Nairobi, Kenya.

[12]. Novemsky, N., Dhar, R., Schwarz, N., and Simonson, I. (2007). Inclination familiarity with decision. Diary of Marketing Research.

[13]. Orodho, L., and Reuben, M. (2002). Exploration system, A bit by bit direct for novices: Sage distribution. London.

[14]. Santos, J. R. A. (1999). Cronbach's alpha: An apparatus for surveying the dependability of scales. Diary of expansion, 37(2), 1-5.

[15]. Van Teijlingen, E., and Hundley, V. (2002). The significance of pilot considers, A Learning Guide; Retrieved from; Routledge, Newyork

[16]. Van Teijlingen, E., \& Hundley, V. (2002). The significance of pilot examines, A Learning Guide; Retrieved from; Routledge, Newyork. 